Logos Universality Mentality Education Novelty, Section: Social Sciences

ISSN: $2284-5747$ (print), ISSN: $2284-5747$

(electronic)

Covered in: CEEOL, Index Copernicus, Ideas

RePeC, EconPapers, Socionet

\title{
A CLUSTER ACCOUNT OF ART EVALUATION
}

\section{Oana VODĂ}

Logos Universality Mentality Education Novelty, Section:

Social Sciences, 2014, Year III, Issue 1, pp: 169-177

Published by:

Lumen Publishing House

On behalf of:

Lumen Research Center in Social and Humanistic Sciences 


\title{
A Cluster Account of Art Evaluation
}

\section{Oana VODĂ $\check{A}^{1}$}

\begin{abstract}
Almost all philosophers who thought about the evaluation of the work of art were limited by one condition: the specific value of an artwork had to be different from any other kind of value (historical, emotional, moral, etc.). If we look very closely at them, these theories of art evaluation are partly also theories of art definition. On the other hand, in the theories of art evaluation there is to be found a constant obssession for the discovery of some criteria in the evaluation that takes the form of universal positive sentences. In this paper I advance, explain and defend, using as a starting point Gaut's cluster account on the definition of art, a cluster account of art evaluation, developed as a relative theory of evaluation, in the sense that a specific work of art is evaluated according to the artistic context in which it has been created. This theory starts from the premise that when we evaluate a particular work of art we already know that object is an artwork and we evaluate it as such, and the artistic object's evaluation is made not by using a strong principle, but by using a number of weak principles, which are not jointly necessary, but are disjunctively necessary for a work of art to have sufficient value as to be considered a good work of art.
\end{abstract}

\section{Keywords:}

art evaluation, art definition, the cluster account.

${ }^{1} \mathrm{PhD}$ Candidate, Faculty of Philosophy and Social-Political Sciences within "Alexandru Ioan Cuza" University, Iasi, Romania, oana_nastasa@yahoo.com.

Voda, O. (2014). A Cluster Account of Art Evaluation. Logos Universality Mentality Education Novelty, Section: Social Sciemces, Year III, Issue 1, 2014, pp. 169-177 


\section{Introduction}

Almost all philosophers who thought about the evaluation of the work of art were limited by one condition: the specific value of an artwork had to be different from any other kind of value (historical, emotional, moral, etc.). If we look very closely at them, these theories of art evaluation are partly also theories of art definition. On the other hand, in the theories of art evaluation there is to be found a constant obsession for the discovery of some criteria in the evaluation that takes the form of universal positive sentences. In this paper I advance, explain and defend, using as a starting point Gaut's cluster account on the definition of art, a cluster account of art evaluation, developed as a relative theory of evaluation, in the sense that a specific work of art is evaluated according to the artistic context in which it has been created. This theory starts from the premise that when we evaluate a particular work of art we already know that object is an artwork and we evaluate it as such, and the artistic object's evaluation is made not by using a strong principle, but by using a number of weak principles, which are not jointly necessary, but are disjunctively necessary for a work of art to have sufficient value as to be considered a good work of art. This theory has a theoretical purpose - it wishes to explain how art evaluation is actually done and to answer some of the dilemmas that have arisen in connection to this subject, as well as a practical purpose - to act as a helpful formula in evaluating a specific work of art.

\section{Essentialism (Generalism) vs. Non-essentialism (Particularism) in art evaluation}

There are two opposite views about art evaluation: the essentialist and the non-essentialist one. To set forth these two options, I will use Robert Stecker's succinct and well-done description ${ }^{2}$. Essentialism in art evaluation takes art value as being: 1. A unitary kind of value; 2 . It is unique to art. Nothing else provides this value; 3 . It is shared by all artworks considered valuable as art across all art forms; 4. It is intrinsically valuable. Nonessentialism in art evaluation takes the contrary to be true: art value doesn't have to be unitary; there is no such thing as a single kind of value that we appreciate when we evaluate an artistic object, different works of art can be valuable for different reasons; we can find values which we traditionally associate with art in objects that are not works of art; art value can be intrinsic, but also extrinsic. Robert Stecker then provides arguments against every

\footnotetext{
2 Stecker, R. (2010). Aesthetics and The Philosophy of Art. An Introduction. Lanham, Boulder, New York, Toronto, Plymouth: Rowman and Littlefield Publishers, p. 222.
} 
principle of the essentialist attitude on art evaluation ${ }^{3}$. I will offer myself some arguments against essentialism in art evaluation, arguments which will throw light on the cluster account of art evaluation and will defend it.

First, nobody managed to produce an art value essentialist theory, so the possibility of finding such a theory is purely theoretical, whilst a practical theory of art evaluation is needed, and would be helpful for practitioners and nonpractitioners alike. Supposing there would be an art value which is to be found in all works of art and only in works of art, nobody managed to identify it. Of course, there were many nominations, starting with Plato's famous art is imitation theory and going through almost every definition of art - art is significant form, art is expression, etc. All those essentialist theories of art paid the price of inadequacy to the actual artistic practice. If we think about art evaluation in essentialist terms, we notice that the endeavor of understanding why art is valuable is the same as understanding why art is art, and that one strong principle which makes a work of art a good work of art is the same principle which includes the object in the artistic object's class. Hence a variety of objects which are in fact works of art but are not recognized as such by some theories of art.

Secondly, when theorists tried to sustain a universal principle of art evaluation, they had to avoid specific artistic criteria as the ones mentioned above (imitation, expression) because the artistic practice had demonstrated that all those were not only not sufficient for a work of art being good, they were not even necessary, there were a bunch of works of art which were not representational nor expressive and which were considered to be good works of art nevertheless. The consequence was that, in searching for that unique kind of value which was to be found in all works of art no matter the time and the place and only in them, circular theories of art evaluation emerged, like: "A work of art is good if and only if the performance of the relevant action on that work by a particular person under appropriate conditions is worthwhile for its own sake" ; "X is a good aesthetic object if $\mathrm{X}$ is capable of producing good aesthetic experiences" .

It is interesting that many of these philosophers start with the hypothesis there are some critical principles which can be applied to works of art - Beardsley for example has that famous trio of criteria according to which a work of art can be judged as being good or bad: intensity, coherence,

${ }^{3}$ Ibidem, pp. 221-246.

${ }^{4}$ Ziff, P. (1979). “Reasons in Art Criticism”. Art and Philosophy, W. E. Kennick (ed.), St. Martin's Press, New York, 683, apud Dickie, G.,(1988) Evaluating Art, Temple University Press, Philadelphia, p. 40.

${ }^{5}$ Beardsley, M. (1958). Aesthetics: Problems in the Philosophy of Criticism, Harcourt, Brace and World, New York, p. 528. 
complexity, but because he searches a strong principle in art evaluation, a principle which is to be found in all good works of art, he climbs up the generalization stairs until he ends up with the term good in the both sides of the definition. So no critical principle or principles which can be applied to all good works of art and only to them has yet been discovered.

\section{Gaut's cluster account}

Gaut developed his cluster account of art definition as an answer to the project of finding a definition of art which states necessary and sufficient conditions for a work to be a work of art. I shall make a description of Gaut's cluster account as it is developed in his Art as a Cluster Concept: a cluster account holds that there can be many criteria (Gaut proposes the term characteristics) for applying a concept, but none of these criteria are necessary. If an object fulfils all the characteristics, than it is part of that class of objects, so the criteria are sufficient for the concept to be applied; and if the object fulfils only some of the characteristics, this theory says this is also sufficient for applying the concept: "there are no properties that are individually necessary conditions for the object to fall under the concept: that is, there is no property which all objects falling under the concept must possess" ${ }^{\text {. }}$. Although there are no individually necessary conditions for applying the concept, there are disjunctively necessary conditions, so that the object has to meet some of the criteria to be included in that concept's class.

\section{A cluster account of art evaluation}

David Graves gives an account, in his The New Institutional Theory of Art, of the systems and subsystems which inhabit the world of $\mathrm{art}^{7}$ and according to which a proper classification is done. I will reduce his description to this sentence: Object $\mathrm{A}$ is a work of art, belongs to the artistic medium $\mathrm{B}$, to the artistic big theory $\mathrm{C}$ and to the artistic working theory $\mathrm{D}$. On the basis of this classification of the work of art we will then interpret and evaluate the work.

First, we will analyse the A factor of the sentence. Because it is a work of art, the object will be evaluated in the specific manner in which all works of art are evaluated - in the context of the art world; in other words, when we focus our attention on that work, we have already classified it as a work of art. We will not do what others tend to do, first to evaluate the work and if the object proves to them to be valuable they conclude the object is art. The

${ }^{6}$ Gaut, B. (2000). "Art as a Cluster Concept". Noel Carroll (ed.), Theories of Art Today, The University of Wisconsin Press, p. 27.

${ }^{7}$ Graves, D. (2010). The New Institutional Theory of Art. Common Ground, Illinois, pp. 51-53. 
inclusion of the object in the art works class has to be finished when we want to artistically evaluate a work, or else we may not know how to look at it, how to interpret it, in fact it would mean we didn't understand it. If we try to evaluate Duchamp's Fountain before knowing that it is a work of art, we would find ourselves in front of a trivial urinal and we will miss the point.

The $\mathrm{B}$ factor deals with the medium in which the work is created, making us take into account the practical aspects of the object. B says what rules makes from an artistic object a painting, for example: it is a visual art work and it is bidimensional. This is an important thing to know when we evaluate the artistic object, because there are some constitutive rules ${ }^{8}$ which are important for a work of art to be a painting, and the criteria we use to evaluate a painting are very different from the criteria we use to evaluate a piece of music.

The $\mathrm{C}$ factor deals with the big theory in which the work has been created and offers another set of constitutive rules which count in its evaluation. To connect the B and C factors, let's think about how important is the bidimensionality of the medium when we analyse objects belonging to different big theories like renaissance and cubism. While the renaissance wishes to recreate the three-dimensional reality on a flat surface using perspective, cubism presents a reality made from geometrical forms, and then from flat forms, in order to respect the original, bidimensional nature of the medium. Thus, the way we interpret and evaluate a renaissance painting should be very different from the way we analyse and evaluate a cubist painting, because these two are created in very different constitutive-rules systems, with different aesthetic and cognitive purposes.

The $\mathrm{D}$ factor, the working theory, offers the most detailed principles of evaluating a specific work of art.

The evaluation of a work of art goes backwards than its classification. The evaluation of a specific work of art will take into account - in this order artist's working theory's rules, big theory's rules and the rules of the medium in which the work has been created. The artist can create the rules of the working theory for himself, or he can borrow someone else's working theory (but if he is a good artist, he will at least contribute to the creation of the rules), but as we climb up to the more general systems of the art world, the evaluative principles will be of a more general kind (very rarely the artist can create his own big theory, although some cases are known), and that leaves room for comparisons among different (but still not completely different) works of art.

The evaluation of a specific work of art can take the following form:

${ }^{8}$ See the discusion normative rules - constitutive rules in Ibidem, pp. 33-35 
A is a work of art

1. A belongs to the working theory $\mathrm{D}$, big theory $\mathrm{C}$, medium $\mathrm{B}$

1.1 D's intentions are the following - they are the evaluative criteria

- Criterion a1

- Criterion b1

- Criterion n1

1.1.1 a1 in the context of $\mathrm{D}$ is always a valuable criterion in the work of art

1.1.2 b1 in the context of $\mathrm{D}$ is always a valuable criterion in the work of art

1.1.3 $\mathrm{n} 1$ in the context of $\mathrm{D}$ is always a valuable criterion in the work of art 1.2. C's intentions are the following - they are the evaluative criteria

- Criterion a2

- Criterion b2

Criterion $\mathrm{n} 2$

1.2.1. a 2 in the context of $\mathrm{C}$ is always a valuable criterion in the work of art

1.2.2. $\mathrm{b} 2$ in the context of $\mathrm{C}$ is always a valuable criterion in the work of art

1.2.3. $\mathrm{n} 2$ in the context of $\mathrm{C}$ is always a valuable criterion in the work of art

2. A meets in some degree some of these criteria: a1, g1, .., n1, h2, ., n2.

3. A has some artistic value.

The measure in which the work of art meets the criteria is essential. If originality is one of this evaluative criteria (and very often it is), it is not enough for the work to have some originality, it has to have a certain degree of originality. If 0 means no originality, and 10 means maximum of originality, we have to establish a way for us to realize if an artistic object has enough originality so that the originality of the work contributes to its positive evaluation. We can arrive to a convention: originality contributes to a work of art being good if it scores 7 or more.

The medium has no specific criteria which contributes to a work's value. $\mathrm{B}$ is mentioned in the formula because it obtains a role in art evaluation only in relation with the big theory and the working theory. If a work of art doesn't meet a constitutive rule of the medium, this does not mean the work is not good or that it loses part of its value, it means only that it belongs to another medium.

This formula must be rewritten for every specific work of art that needs evaluation. Thus, it has to be filled with the specific data: what is the working theory, the big theory, the medium, the evaluative criteria a1, b1, a2, b2, etc. To show how this formula works, we will take Carlo Carra's Il Funerale dell'anarchico 
Galli $^{9}$ as an example. The first step is to correctly classify it, so we can then correctly evaluate it. It is easy to notice this is a picture and that it belongs to Futurism, the working theory being Italian Futurist painting. The principles of Italian Futurism in painting will be the first evaluative principles that we take into account. This is quite easy to do, because the futurists developed manifestos to explain their artistic view. The Technical Manifesto of Futurist Painting $^{10}$ advances the following intentions: originality (a1), antirepresentationality (b1), anti-harmony and anti-good taste (c1), themes from the present or the future - speed, steel, etc. (d1), innate complementarity in composition (e1), dynamism (f1), sincerity and purity (g1), anti-materiality (h1). We then take into consideration the more general principles of Futurism: the glorifying of the future - technological development, speed, objects like the car, the industrial city (a2), the feeling of youth (b2), courage, dare, rebellion, violence, aggressiveness (c2), the triumph of technology over nature (d2), originality (e2), freedom from the past (f2).

In his work, Carlo Carra depicts the funeral parade of Angelo Galli, a worker killed during a strike, parade which eventually turns into a confrontation between the police and the anarchists. The subject meets criteria like c2, f2 - it is about an event from the recent past with great influence over present and future, a first step to demolish the status-quo (f2). The fact that it actually has an historical theme, along with the big dimension of the painting, makes the spectator think about a traditional historical painting; the composition also shows a clasic source of inspiration, and this works against the declared intentions of futurism (f2, a1). At a stylistic level, attention is first drown by Galli's red coffin, which is surrounded by a chaotic explosion of characters dressed in black (f1) - the anarchists, who are enlightened and rendered almost transparent - dematerialized - by the light which comes from the sun and from the coffin. The light emphasise their aggressive movements (d1, h1, c2, f2). The spectator feels like he is at the centre of the painting (f2), and the fact that the perspective is fractured, although comes from a cubist source of inspiration, doesn't go against the principles of futurism, on the contrary, adds dynamism to the painting. On the basis of this analysis and following closely the measure in which the working theory and the big theory's principles are fulfilled, we can arrive at the conclusion that this work of art is a good one, a work which succeeds in what it had intended. It is important to notice that not all the criteria of the artistic subsystems must be fulfilled, it is sufficient that some of them be fulfilled in a good measure to make the work of art count as a good

${ }^{9} \mathrm{http} / /$ www.moma.org/collection/browse_results.php?criteria=O\%3AAD $\% 3 \mathrm{AE} \% 3 \mathrm{~A} 987 \& \mathrm{pa}$ ge_number=1\&template_id=1\&sort_order $=1$

${ }_{10}$ http://www.unknown.nu/futurism/techpaint.html 
one, thus these conditions are disjunctively necessary for the artistic object to be valuable. The viewer's aesthetic experience when regarding this painting is closely linked with the principles in which the painting is created, he has to know what he is looking at, if not, he will not understand and thus he will not be able to interpret and evaluate. This kind of thing happens many times, when spectators of such a work, not knowing about modern art or about futurism, try to understand it by using principles from other artistic movements - especially traditional principles like harmony and imitation. Of course these people will arrive at the conclusion that it is a bad work of art (or not art at all).

\section{Conclusions}

As we have seen above, there are very different reasons which count for an artistic object being good. The cluster account of art evaluation explains not only how different the reasons for evaluating specific works of art can be, but also explains why we evaluate differently works of art quite similar or even belonging to the same artistic movement. Usually, the criteria in a working theory (a1, b1) are likely to be fulfilled in their majority by works of art belonging to that specific working theory, if not, the work would cease to belong to that theory, whilst the big theory's criteria $(\mathrm{a} 2, \mathrm{~b} 2)$ would be fulfilled in a lesser degree. Although there are some strong principles of evaluation inside a big theory and especially a working theory (and only there) - actually the constitutive rules as explained by Graves, not all the working theory's criteria are necessary for the work of art being valuable, and if we consider the big theory, except for the first work/works which established the movement, the works would fulfil only some of the initial rules. And of course, it is not only about the principles of evaluation, it is also very much about the measure in which these principles are fulfilled.

There is an infinite number of evaluative criteria, and they can be contradictory, self-denying, based on the big theory in which the work belongs, that's why there is no universal principle to confer value on all works of art. The cluster account of art evaluation finds its inspiration in Gaut's cluster account on definition of art, but while Gaut offers ten criteria (although he does not mention that these are the only ones) which are disjunctively necessary for a work to be a work of art, this theory cannot offer ten criteria which, disjunctively, find themselves in all or almost all the works of art that are good. The reason is that artistic objects are so different one from another, the artistic movements have so different intentions and purposes, that it is impossible to discover a set which, even disjunctively, matches all good works of art. Even if such a set would be discovered, there is nothing to guarantee that it would be suitable also for the art of the future. 


\section{REFERENCES}

Beardsley, M. (1958). Aesthetics: Problems in the Philosopby of Criticism. New York: Harcourt, Brace and World.

Dickie, G. (1988). Evaluating Art. Philadelphia: Temple University Press.

Gaut, B. (2000). "Art as a Closter Concept". In Carroll, N. (ed.), Theories of Art Today, The University of Wisconsin Press.

Graves, D. (2010). The New Institutional Theory of Art. Illinois: Common Ground.

Stecker, R. (2010). Aesthetics and The Philosophy of Art. An Introduction. Lanham, Boulder, New York, Toronto, Plymouth: Rowman and Littlefield Publishers.

Voda, O. (2014). A Cluster Account of Art Evaluation. Logos Universality Mentality Education Novelty, Section: Social Sciemces, Year III, Issue 1, 2014, pp. 169-177 